\title{
DONOS DO PODER? OS LIMITES E CONFLITOS DA ATIVIDADE PERICIAL FRENTE AO ESTABELECIMENTO DE NEXO NO ATUAL CONTEXTO DA PREVIDÊNCIA SOCIAL BRASILEIRA
}

\section{OWNERS OF THE POWER? THE LIMITS AND CONFLICTS OF FORENSIC WORK FOR THE ESTABLISHMENT OF NEXUSES OF CAUSE IN THE CURRENT CONTEXT OF THE BRAZILIAN PUBLIC WELFARE SYSTEM.}

\author{
Davidson Passos Mendes, $\mathrm{Ms}^{1}$; Eliza Helena de Oliveira Echternacht, Dra ${ }^{2}$ \\ ${ }^{1}$ Federal University of Minas Gerais - DEP/UFMG - Belo Horizonte - Brasil davidson.prof @ newtonpaiva.br \\ ${ }^{2}$ Federal University of Minas Gerais - DEP/UFMG - Belo Horizonte - Brasil eliza@dep.ufmg.br
}

\begin{abstract}
Resumo
Frente às demandas de compreensão da atividade do perito do INSS e as polêmicas quanto aos poderes e limites desse trabalho, este artigo objetiva refletir sobre as condições de execução, os sistemas com que lidam, bem como o poder decisório de cada um no atual contexto da previdência. Foi estabelecido foco sobre o processo de trabalho na Perícia Médica previdenciária em busca de elementos de resposta a uma demanda social acerca do sub-registro das doenças profissionais $e$ sobre o estabelecimento do nexo de causalidade. Foram utilizados para análise e coleta de dados, através do método da AET (Análise Ergonômica do Trabalho), dois peritos oficiais do sistema e observadas as estratégias de tomada de decisão para a concessão/negação do beneficio. Os resultados mostram que as relações que se estabelecem entre os peritos e as interfaces com que lidam, traduzem as estratégias utilizadas e as formas singulares dos usos de si. Demonstram também que a negativa de um benefício não depende somente do agir pericial, mas de um conjunto de processamentos administrativos e técnicos que impactam na eficiência do sistema de beneficios.
\end{abstract}

Palavras-chave: perito do INSS; auxílio-doença; competência.

\section{Introdução}

O objetivo deste artigo é refletir sobre as atuais condições de execução da atividade pericial no contexto da Previdência Social Brasileira, apontando os possíveis efeitos de tais condições sobre a eficiência do Sistema de Benefícios, especialmente no que se refere ao estabelecimento de nexos de causalidade entre a doença incapacitante e o trabalho. O nexo de causalidade é que estabelece a relação de causa e efeito entre o adoecimento e o trabalho.

A instituição responsável pelo estabelecimento desse nexo e o conseqüente reconhecimento formal da doença profissional e do acidente do trabalho é a previdência social (INSS), que é um dos 
pilares da seguridade social. É uma instituição pública, de regime geral, filiação obrigatória para quem possui relação formal de emprego e de caráter contributivo cujo objetivo é o de fiscalizar e arrecadar as contribuições, além de reconhecer e conceder direitos aos seus segurados (INSS, 2005).

O trabalhador segurado para ter acesso ao benefício de auxílio-doença, que é um benefício concedido ao segurado portador de uma incapacidade para o trabalho, deve ser avaliado pela Perícia Médica.

As deficiências estruturais da perícia médica previdenciária como a dificuldade diagnóstica da relação saúde/trabalho, a relação desigual entre a demanda pelo benefício de incapacidade e a carência de peritos, o caráter deficitário da Previdência, dentre outras, trarão conseqüências importantes sobre o estatuto do doente profissional, fomentando as estratégias de ocultamento de sintomas pelos trabalhadores, dificultando o diagnóstico e o registro das doenças ocupacionais (subregistro) (MENDES, 2006).

Em torno da atuação do médico perito surgem várias polêmicas quanto ao exercício, poderes e limites deste trabalho (VERTHEIN, 2001; MELO, 2003).

No âmbito da instituição, conflitos são vivenciados na avaliação do segurado para a concessão de benefícios, como exemplo, em divergências vivenciadas no entendimento dos procedimentos técnicos e sua aplicação, baseado no conjunto normativo e suas derivadas conseqüências; discordância e insatisfação dos segurados quando os benefícios são negados, dentre outros. As divergências quanto aos resultados das avaliações periciais tornam-se ainda mais intensas quando se toma como foco o debate social suscitado em torno de patologias relacionadas ou provocadas pelas condições de trabalho.

Para tentar compreender o modo pelo qual esses profissionais selecionam variáveis em interfaces distintas (perito-sistema informatizado, perito-paciente, perito-norma, perito-perito), um estudo acadêmico está sendo desenvolvido visando identificar os condicionantes dessa atividade, focalizando os limites e as contingências dessa representação (relação saúde/trabalho). Neste artigo, partiremos da análise da atividade de dois peritos em situação real de trabalho e buscaremos identificar e discutir os contextos de tomada de decisão frente às características tecnoorganizacionais deste sistema produtivo.

\section{Metodologia}

A abordagem metodológica utilizada, de caráter qualitativo, priorizou a observação das situações reais de trabalho de seis médicos peritos, usando a Análise Ergonômica do Trabalho (GUÉRIN et al, 1997) em Agências da Previdência Social (APS) de uma cidade brasileira de grande porte. A agência escolhida para análise possui porte A (maior quantidade de benefícios concedidos). A 
atividade dos peritos foi observada durante quatorze meses, em três etapas, divididas segundo a metodologia adotada. Neste artigo optamos por focalizar a discussão em dois peritos que foram escolhidos para análise por apresentarem qualificações (formações) diferenciadas e vínculos distintos com o INSS. O perito I é homem, especialista em Medicina do Trabalho e funcionário efetivo da instituição e o II é mulher, especialista em Clínica Médica, credenciada. Ambos tinham outro vínculo empregatício. O foco das observações centrou-se na tomada de decisão do ato pericial no qual se espera uma opção decisória. Após a coleta dos dados, foram realizadas confrontações com os peritos.

\section{O processo de trabalho na Perícia Médica}

Dentre os benefícios previdenciários daremos enfoque no benefício por incapacidade laborativa ou auxílio-doença. Este se destaca por seu caráter de prestação continuada e temporária, dependente em sua operacionalização, nas fases de reconhecimento, manutenção e revisão do benefício, de um corpo técnico composto por médicos - a perícia. Para ser deferido o pedido do benefício deve ser caracterizada a incapacidade para o trabalho e em casos de acidente de trabalho deve ser emitida a CAT (Comunicação de Acidente de Trabalho). Na avaliação pericial o resultado é dado no momento da perícia. Na primeira perícia, chamada de AX1 (avaliação inicial) é que se preenche a probabilidade diagnóstica e se estabelece a data do inicio da doença (DID) e a data do início da incapacidade (DII). É feita uma anamnese ocupacional e realizado o exame físico, além do preenchimento do prontuário (Sistema SABI). Nesse momento há dois caminhos para a tomada de decisão: indeferir o pedido do benefício por ausência de incapacidade ou estabelecer o benefício que pode ser auxílio-doença previdenciário (ADP) ou acidentário (ADA). Para se estabelecer o ADA deve-se ter a CAT emitida pelo médico do trabalho da empresa. Em qualquer outra situação se estabelece o ADP. Os peritos que farão as perícias posteriores seguem a perícia inicial e as informações são compartilhadas entre os peritos via sistema microeletrônico. $\mathrm{Na}$ atividade pericial, cada perito faz interface com outros pares médicos, que são assistentes do segurado. Essa interface se dá via laudo e relatórios de exames diagnósticos. A perícia final (aposentadoria por invalidez) é definida pelo perito supervisor, que é o responsável pela definição do quadro, após ser liberado pelo sistema SABI para aposentadoria. Após a perícia inicial (AX1), se concedido o auxílio-doença, seja acidentário ou previdenciário, o segurado passa por reavaliações (re-perícias) periódicas com o intuito de se avaliar a permanência ou não da incapacidade e a possibilidade de retorno do segurado ao trabalho. Após a primeira perícia, o segurado já possui as informações relativas ao adoecimento que provocou a incapacidade para o trabalho, disponibilizadas no sistema. Ao segurado cabe provar que permanece a incapacidade para o trabalho para que continue a ter direito ao benefício 
concedido. O segurado chega à perícia com o laudo do médico assistente e através do sistema SABI, o perito irá confrontar as informações do laudo, da queixa do paciente, com as informações fornecidas pelos peritos que anteriormente tenham atendido aquele segurado.

A cada perícia há dois caminhos possíveis para o perito tomar decisão. Um caminho é suspender o benefício e retornar o indivíduo ao trabalho. Poderá suspender o benefício de imediato ou manter o afastamento de trabalho por um certo período com previsão de alta.

O outro caminho é manter o indivíduo afastado do trabalho (manutenção do benefício) com a marcação de uma nova perícia.

\section{Os elementos, o objeto e os meios de trabalho na Perícia Médica}

\subsection{Os peritos}

Os peritos são profissionais com formação médica, responsáveis pelo reconhecimento formal da incapacidade para o trabalho e a conseqüente liberação ou não do benefício solicitado pelo segurado.

Os peritos podem ser oficiais, pertencentes ao quadro de pessoal efetivo do INSS, nomeados via concurso, ou credenciados (contratados) que trabalham como mão de obra auxiliar ao pessoal permanente. Os peritos oficiais atendem em consultórios nas agências do INSS e os credenciados em consultórios particulares utilizados para fins de perícia.

Os peritos oficiais trabalham em regime de dedicação exclusiva com carga horária semanal de 40 horas ou 24 perícias/dia, embora haja peritos oficiais, minoria, com jornada de 20 horas semanais ou 12 perícias/dia. O perito segue a produtividade exigida a cada dia e se absorver essa demanda num tempo inferior às oito horas/dia é liberado. Vale aqui lembrar que todos os peritos estudados possuem outro vínculo empregatício.

Os peritos credenciados atendem o número de perícias agendadas previamente pelas agências da previdência. Há casos de mais de 24 atendimentos/dia, embora atualmente haja uma limitação ao número de perícias/dia realizadas pelo credenciado.

Entre os peritos há uma diversidade de formações, com especializações nas mais diversas áreas, da clínica médica, medicina do trabalho, às especialidades cirúrgicas.

É esperado que o sujeito perito possua competências de avaliar o segurado e a atividade de trabalho desse segurado. As perícias são marcadas aleatoriamente a cada perito. $\mathrm{O}$ sistema de gestão de benefícios opta pela marcação entre os peritos oficiais e na impossibilidade dessa marcação, a perícia é direcionada aos terceiros. Não há uma relação entre a patologia e a incapacidade apresentada pelo segurado e a especialização dos peritos. Cada perito atende e age nas mais diversas 
patologias, sem relação direta com sua formação.

\subsubsection{Objeto e Meios de Trabalho}

O objeto de trabalho do perito é o segurado da previdência. O segurado é o sujeito trabalhador, contribuinte do sistema previdenciário, seja relação formal de emprego, com desconto em folha ou como autônomo.

Com a desigualdade social e de renda há uma população distinta de segurados, com formações diversificadas, de analfabetos a profissionais de nível superior, de classe baixa a médiaalta, embora a grande maioria seja constituída de uma população de baixo nível de escolaridade e renda não superior a três salários mínimos (INSS, 2005). Devido ao baixo nível de escolaridade e renda é uma minoria que questiona os procedimentos periciais numa tentativa de ver respeitado o próprio direito à cidadania.

Os peritos possuem como meio de trabalho, um sistema de base microeletrônica denominado Sistema SABI (Sistema de Administração de Benefícios por Incapacidade) e as normas técnicas (Normas Técnicas de Avaliação da Incapacidade) que regulam e regulamentam a atividade pericial.

O conteúdo normativo de cada norma inclui o critério de caracterização pericial e de nexo com o trabalho, além de critérios diagnósticos clínicos, baseados na história clínica ocupacional, no exame físico e em exames diagnósticos, quando justificáveis.

Nesta relação (perito-segurado) surgem conflitos. Conflitos gerados pela insatisfação do segurado quanto à decisão em relação à concessão ou não do benefício. O perito, através das interfaces com que lida, busca informações para a montagem de suas representações que subsidiarão a tomada de decisão.

\section{A atividade e as tomadas de decisão}

O propósito da Perícia Médica é definir, baseando-se em laudos diagnósticos e na experiência do perito, a concessão/negação da incapacidade, do nexo da doença com o trabalho e o benefício que será devido ao trabalhador.

Como citado por um perito oficial do INSS: 
A perícia é uma forma técnica de liberar benefício por doença, doença grave. E para a caracterização crítica, digamos assim, na avaliação do grau de doença, do quanto isso é incapacitante para o segurado ele tem que fazer uma perícia (...) não faz diagnóstico, não faz tratamento, a gente só avalia o grau de incapacidade do segurado. Quanto tempo, provavelmente terá esta incapacidade e qual o grau. Se ela permite retornar a atividade laborativa ou não.

Os dois casos demonstrados e posteriormente analisados estão subordinados à gerênciaexecutiva de uma grande cidade. Através dos casos objetivar-se-á analisar e discutir as margens de manobra, de ação e regulação desses sujeitos frente aos condicionantes da atividade pericial, ou seja, a forma pela qual o sujeito, dependente das competências, renormaliza, transgride, geri conflitos e age.

\subsection{Situação 1: Perito I}

Perito I: Homem, 58 anos, especialista em Medicina do Trabalho. É perito oficial do INSS há 28 anos. O regime de trabalho é de $40 \mathrm{~h} /$ semanais ou 24 perícias/dia. Possui outro vínculo empregatício.

Paciente - segurado - trabalhador: Mulher, 24 anos, solteira, de aparência humilde. Trabalha como caixa de supermercado há quatro anos.

Diagnóstico do médico assistente: LER/DORT

Diagnóstico funcional: limitação funcional e incapacidade do membro superior direito (MSD)

\subsubsection{Caso 1:}

O perito solicita a guia de marcação da perícia e via NIT (Número de Identificação do Trabalhador) entra no sistema SABI.

Observa o prontuário, colhe informações e interage com a segurada.

\begin{tabular}{|c|c|}
\hline Perito & Segurada \\
\hline Onde você trabalha? & No $\mathrm{x}$ supermercado \\
\hline Com o que? & Operadora de caixa \\
\hline O que sente? & Dor no braço Direito \\
\hline & $\begin{array}{l}\text { *A segurada entrega a CAT (Comunicação de Acidente de } \\
\text { Trabalho) ao perito. }\end{array}$ \\
\hline Quem emitiu a CAT? & A médica da empresa \\
\hline $\begin{array}{l}\text { A médica caracterizou o nexo. A firma vai concordar, } \\
\text { mas não assinou. Não vou colocar no sistema porque } \\
\text { a firma não assinou. }\end{array}$ & \\
\hline A médica é da empresa? & Sim \\
\hline Então a empresa vai assinar. & \\
\hline Tira a blusa! & Não dou conta \\
\hline O braço está caído? & Sim e dói muito. \\
\hline $\begin{array}{l}\text { Guarde esses exames porque você vai precisar deles } \\
\text { mais tarde. }\end{array}$ & \\
\hline O que você acha que provocou isso? & O ortopedista falou que é movimento repetitivo demais. \\
\hline Há quanto tempo você está lá? & Quatro anos \\
\hline $\begin{array}{l}\text { Estando a CAT 'arrumadinha' aí nós a cadastramos. É } \\
\text { só você mandar a firma assinar, carimbar e voltar } \\
\text { aqui. }\end{array}$ & \\
\hline *Volta no Sistema SABI, faz anotações e mantém o aux & álio-previdenciário com uma reperícia (retorno) em trê \\
\hline $\begin{array}{l}\text { Você vai voltar aqui daqui a três meses para uma } \\
\text { nova perícia }\end{array}$ & \\
\hline
\end{tabular}

\footnotetext{
${ }^{*}$ Comentário do pesquisador
} 
O perito I comenta com o pesquisador: "O que facilita muito o meu trabalho é também porque já fui perito do funcionalismo. A experiência te faz montar estratégias para agir. Não adianta colocar determinados indivíduos para trabalhar porque não vai dar conta".

E continua verbalizando com o pesquisador: "Esses exames NEER, FILKEINSTEIN a gente sabe fazer. Não se faz porque o quadro dela é característico".

Em entrevista de auto-confrontação (GUÉRIN et al, 1997), o perito é questionado a respeito do por quê o benefício concedido não ser o acidentário e sim o previdenciário. De acordo com o perito: "Para a empresa não interessa emitir a CAT. Para a gente pouco importa. Nesse último caso não foi emitida a CAT, porque não está assinada pelo médico da empresa, portanto, não é considerado acidente de trabalho".

Ainda de acordo com o perito foi estabelecida a incapacidade, porém não se estabeleceu a relação com o trabalho. Somente será concedido o benefício acidentário com a CAT completa. E observa que a CAT somente é aceita se for feita pelo médico da empresa.

"Não aceitamos a CAT do sindicato. A empresa entra na justiça e o juiz pergunta se quem emitiu a CAT visitou a empresa. Como não visitamos, dançamos".

\subsection{Situação 2: Perito II}

Perito II: Mulher, 42 anos de idade, especialista em Clínica Médica.

A médica é credenciada do INSS há dois anos. Atende em seu consultório que está interligado à seguridade via sistema SABI. Realiza em média 24 perícias-dia, agendadas pelas agências do INSS. Está subordinada à gerência-executiva de uma capital através do GBENIN (Gerência de Benefícios por Incapacidade). Possui outro vínculo empregatício. Atende pacientes em consultório particular, mesmo local de realização das perícias, além de plantões em hospitais.

Paciente - segurado - trabalhador: Paciente mulher, empregada, 38 anos, com diagnóstico de Síndrome do Túnel do Carpo.

\subsubsection{Paciente II: Caso 2}

Paciente mulher, 38 anos, afastada desde junho 2004, doméstica. Possui emprego formal.

A paciente entra no consultório.

A médica solicita a identidade e a guia de marcação da perícia.Via NIT entra no sistema SABI e abre o prontuário da segurada.

Diagnóstico médico: Síndrome do Túnel do Carpo

A médica inicia a avaliação pericial.

*Verbaliza em voz alta as informações colhidas do Sistema SABI. Paciente mulher, 38 anos, afastada desde junho 2004, doméstica. Possui emprego formal. Já solicitou o benefício de incapacidade por três vezes: março de 2001, afastada até dezembro de 2001; março de 2002 até setembro de 2003; junho de 2004 até a perícia de hoje. Esta é a quinta perícia da segurada nesse último período de afastamento.

\begin{tabular}{|l|l|}
\hline \multicolumn{1}{|c|}{ Perito } & \\
\hline Qual a sua profissão? & Doméstica. \\
\hline Está empregada? & Sim \\
\hline *Solicita o laudo e exame complementar. & \\
\hline $\begin{array}{l}\text { No sistema SABI colhe as informações de emprego, } \\
\text { de medicamentos utilizados e de tempo de } \\
\text { contribuição. }\end{array}$ & \\
\hline
\end{tabular}




\begin{tabular}{|l|l|}
\hline O que você sente? & Dor no punho e formigamento no braço. \\
\hline Nos dois? & No braço direito é pior, mas está começando no esquerdo. \\
\hline Já fez tratamento? & Fiz cirurgia no punho há seis meses. \\
\hline Está melhor? & Não. \\
\hline $\begin{array}{l}\text { *Defere a continuidade de afastamento por três meses } \\
\text { com previsão de alta. }\end{array}$ & \\
\hline
\end{tabular}

A paciente sai da sala. A médica foi questionada do por quê da alta da paciente e verbaliza:

A segurada já realizou cirurgia e não relata melhora. Não é possível assim. Esse povo tem que voltar ao trabalho. A última perícia que foi realizada já estipulava alta, porém o perito oficial quis dá-la mais tempo de recuperação e solicitou à próxima perícia a possibilidade de alta. Como não houve mudança de quadro, resolvi seguir as orientações.

Pesquisador: A paciente estava afastada com auxílio-acidentário?

Perito: Não. Previdenciário. Ela não tinha CAT emitida, portanto se estabelece o Previdenciário.

\section{Análise}

As análises de situações de trabalho realizadas pela ergonomia da atividade e pela ergologia consideram de modo particular a distância sempre existente entre as prescrições das tarefas a serem realizadas e o trabalho real.

Com efeito, para estas abordagens do trabalho humano, "diferentemente de uma dispersão estatística mais ou menos controlada, a variabilidade no trabalho aparece como matriz permanente de uma história que ninguém domina”. (SCHWARTZ, 1997, p. 28). No sistema taylorista, “a variabilidade é constatada, mas para ser recuperada, ou mesmo neutralizada". (SCHWARTZ, 2000, p. 353)

Nas situações analisadas neste estudo não há como fazer uma negação da subjetividade. Em todas as situações analisadas, faz-se apelo a uma atividade humana situada e confrontada à historicidade dos eventos, incorporando competências particulares, capazes de lidar com o singular, os imprevistos e os fatos atípicos, tendo como objeto de trabalho um sujeito trabalhador inserido em sistemas produtivos diversos, com formas distintas de adoecimento e com uma especificidade em comum: a dificuldade de se estabelecer o diagnóstico em doenças relacionadas ao trabalho. Além da variabilidade do objeto (sujeito trabalhador), há uma diversidade de formações dos peritos, com saberes, vivências e valores distintos, além da diversidade de vínculos com a instituição.

O trabalho pericial possui 'normas antecedentes' que são as Normas Técnicas de Avaliação da Incapacidade e as 'normas de qualidade'. Estas normas estruturam e direcionam as representações para a tomada de decisão da concessão ou não do benefício. As Normas Técnicas são utilizadas para normatizar e regulamentar os procedimentos médico-periciais. Associado às 
normas técnicas do INSS, é fato também as normas internas, 'os acordos' estabelecidos na instituição, que se tornam normas antecedentes da atividade pericial para os procedimentos operacionais, produtivos e de qualidade exigidos pela instituição de seguridade (INSS). São exigências implícitas, tais como o não estabelecimento de nexo, não concessão de benefícios, não informação dos direitos do segurado, a negativa da CAT (se não emitida pelo médico da empresa), estabelecidas internamente e que são necessárias para a avaliação da qualidade e do desempenho da atividade pericial. O Sistema Sabi é uma operacionalização das 'normas de qualidade'. Por ele é determinado as patologias que geram afastamento, o tempo médio de concessão do benefício para cada patologia e os critérios de concessão de auxílio-doença. O sistema atua como encarceramento, um gesso da atividade pericial. A estrutura de produção de perícias, com o parcelamento da atividade pericial, fragmenta a decisão. A cada perícia o segurado se torna dependente da forma pela a qual o perito se apropria das normas técnicas e das normas de qualidade para montar as suas estratégias de tomada de decisão. O principal objetivo das normas de qualidade é a negação do benefício. As 'normas de qualidade' são uma renormalização das normas técnicas, estabelecidas institucionalmente. A prática da produção de perícias em alguns pontos confronta com o estabelecido nas normas técnicas.

Portanto, a atividade pericial situa-se entre um conflito de normas, as normas internas da instituição ('normas de qualidade') e as normas técnicas que regulamentam as condições para o estabelecimento do nexo entre a doença e o trabalho.

As renormalizações poderão ocorrer sobre os 'poros' deixados pelas exigências implícitas da atividade e pelas normas técnicas. A dramática da atividade acontece nas micro-escolhas, nos caminhos a seguir, nas renormalizações de normas antecedentes, respeitando as exigências de qualidade da atividade que é a restrição à concessão do benefício, além dos critérios de produtividade, fato necessário para não ser punido administrativamente.

A apropriação das normas técnicas e das 'normas de qualidade' e a sua ressignificação é dependente da competência do sujeito. Para agir e tomar decisão o perito se apropria dessa competência que é singular, dependente dos saberes, das vivências com a situação e com os valores atribuídos à posição. Através da competência, o sujeito hierarquiza as informações necessárias e válidas para a tomada de decisão. O perito I se utiliza da experiência como médico do trabalho e estabelece as hierarquizações que julga necessárias à decisão. Não realiza os testes especiais conforme citado e relata as vivências anteriores como atributos para a tomada de decisão. Relata também as vivências, a experiência com a situação: "Você vai passando tanto tempo na perícia que consegue externar o lado do paciente e solicitar exames e ele nem aparece aqui mais".

No caso II, o perito evita transgressões como forma de gestão de conflitos. Segue as normas implícitas da instituição e as avaliações anteriores contidas no Sistema Sabi. 
Conforme verbalizado pelo perito: "Procuro não ter conflito com os outros peritos. Geralmente os peritos colocam observações para as próximas perícias e geralmente as sigo".

O perito também revela hierarquizações para a decisão como a situação de trabalho do segurado (empregado ou não), história de afastamento e o laudo. Há uma hierarquização de valores acerca do laudo, conforme verbalizado pelos peritos:

"Eu observo nos laudos o CID, o quadro atual e o nome do médico que assinou. O laudo depende do local. Se for referência em tratamento é bom. O laudo do SUS é mais confiável porque não é comum comprá-lo".

De acordo com os saberes, na situação I o sujeito perito é especialista em Medicina do Trabalho. Este atributo da competência, de forma singular e situada, amplia os campos de ação e regulação do sujeito neste contexto. Como verbalizado:

"O que facilita muito o meu trabalho é também porque já fui perito do funcionalismo. A experiência te faz montar estratégias para agir. Não adianta colocar determinados indivíduos para trabalhar porque não vai dar conta. Já fiz caracterização de LER, já realizei análise ergonômica. O fato de ser médico do trabalho e já ter passado por experiência anterior facilita o meu trabalho aqui. Tenho representações com a experiência acumulada".

Na segunda situação, o perito é credenciado. Possui pouco tempo de trabalho como perito e atende em consultório particular. Seus campos de possibilidade de ação e regulação dentro dos condicionantes da atividade são restritos, porque ainda não têm uma vivência, uma historicidade com a situação. A ressignificação das normas técnicas e dos 'acordos' internos é mínima. Evita transgredir para não ser punido. As renormalizações possíveis, evidenciadas na análise se dão pela alta produção de perícias, em que cada avaliação pericial demora no máximo 4 minutos. Traduz a ressignificação das normas em uma intensificação e aceleração do trabalho. Como evidenciado na situação II:

"O perito que fez a AXI caracterizou o adoecimento e relatou o tempo de melhora provável. Segui basicamente a avaliação inicial e dei andamento. Procuro não ter conflito com os outros peritos. Geralmente os peritos colocam observações para as próximas perícias e geralmente as sigo".

Dessa forma, observa-se que as renormalizações não são amplas e sempre possíveis. É dependente da vivência, dos valores e dos saberes de cada sujeito com a situação dada.

A competência de cada sujeito pode ampliar ou reduzir os campos de possibilidades de ação e regulação através das renormalizações, das transgressões. A historicidade faz com que o sujeito monte representações. A vivência faz com que o sujeito se articule e saiba burlar as exigências da instituição e do segurado. O sujeito competente amplia a ação numa tentativa de atingir os objetivos da instituição, negar ou suspender o benefício, como também voltar atrás quando confrontado com um segurado instruído. $\mathrm{O}$ perito com menos vivência evita transgredir. Busca seguir os 
procedimentos adotados por peritos que possuem uma historicidade maior com a situação. $\mathrm{O}$ fato de ser perito oficial ou terceiro também atua como fator de restrição dos campos de regulação da carga de trabalho.

\title{
6. Considerações finais
}

As variações encontradas nos modos operatórios nos indicam que o exercer a atividade de perito depende de constantes negociações com as normas antecedentes e também da competência do sujeito com a situação dada. Conforme SCHWARTZ, as competências são situacionais e estabelecidas de acordo com a qualificação, historicidade do sujeito, seus valores, projetos-herança e a capacidade de patrimoniar (ver SCHWARTZ, 1998).

A importância desse artigo se dá na oportunidade de demonstrar os usos de si de dois atores sociais (peritos) frente aos condicionantes do contexto pericial. São possibilidades de ação e regulação distintas frente às condicionantes distintas. Esse artigo é foco de um estudo acadêmico maior e requer um aprofundamento das questões. Mais estudos devem ser feitos para que se possa repensar a estruturação pericial do INSS.

\begin{abstract}
Due to the demands of comprehension of the activity of the INSS forensic expert, the polemics as to the powers and limits of this job, this paper aims at reflecting on the conditions of performance of the activity of that professional; the system which the forensic expert deals; as well as the power for decision making of each one of them in the current context of Previdência (Brazilian Federal Social Security Agency). It has been established a focus on the working process in the medical forensic department in pursue of the elements which would give an answer to a social demand on the subregister of the professional diseases, and about how their cause are established. It has been used for data collection, through the methodology of AET (Ergonomic Task Analysis) two forensic experts from Previdência, and the strategies for decision making regarding the concession or denial of benefits were observed. The result shows that the relations that are built and the interfaces which the experts deal with, reveal the strategies used and the personal ways of self use. They also show that the denial of a benefit does not depend only on the forensic activity itself, but on a range $o$ administrative processing and technician, which have an impact on the efficiency of the benefit system.
\end{abstract}

Key-words: INSS forensic expert; disease support; competency.

\section{Referências}

ECHTERNACHT, E. H. Alguns elementos para a reflexão sobre as relações entre Saúde e Trabalho no Brasil. Revista Brasileira de Medicina do Trabalho, v.2, n.2, p. 85-89, abr-jun 2004. 
GUÉRIN, F., LAVILLE, A., DANIELLOU, F., DURAFFOURG, J. \& KERGUELEN, A. Comprende le travail pour le transformer - La pratique de l'ergonomie. Paris: ANACT, 1997.

INSTITUTO NACIONAL DE SEGURIDADE SOCIAL - INSS. A Previdência Social. Brasília, 2005. Disponível em: $<$ http://www.mpas.gov.br>. Acesso em: 10 abr. 2005.

LIMA, F. P. A \& SCHWARTZ, Y. Normalisations e renormalisations: modèles dynamiques de la prescription et historicité dês situationns de travail. In: Actes du XXVII èmes Congrés de la Société d'Ergonomie de Langue Française: "Le évolutions de la prescription", Aix-en-Provence, 25-27 de setembro, 2002.

MELO, M. P. P. \& ASSUNÇÃO. A. A. A racionalidade médico-pericial na avaliação da incapacidade laborativa do segurado da Previdência Social. Revista de Saúde Coletiva do Instituto de Medicina Social da Universidade Estadual do Rio de Janeiro, 2003.

MENDES, D.P; ECHTERNACHT, E.H. Donos do Poder? Uma análise da atividade pericial no contexto da Previdencia Social Brasileira: limites e conflitos frente à caracterização do adoecimento em LER/DORT. Dissertação de mestrado, PPGEP/UFMG, 2006. 131 p.

SCHWARTZ, Y. Os ingredientes da competência. Um exercício necessário para uma questão insolúvel. Campinas. Educação \& Sociedade, V.19, n 65, 1998.

SCHWARTZ, Y. Trabalho e uso de si. In: Revista Proposições (Unicamp), vol 11, julho 2000, pp 34-50.

SCHWARTZ, Y. Trabalho e gestão: níveis, critérios, instâncias. DP\&A, 2001. p. 23-33.

SCHWARTZ, Y. Circulações, Dramáticas, Eficácias da Atividade Industriosa. Trabalho, Educação e Saúde, v.2, p. 33-55, 2004.

VERTHEIN, M. A. R. \& GOMES, C. M. As armadilhas: bases discursivas da neuropsiquiatrização das LER. Ciência e Saúde Coletiva, Rio de Janeiro, v. 6, n. 2., p. 457-470, 2001.

\section{Dados dos autores:}

Davidson Passos Mendes

Professor convidado - Departamento de Engenharia de Produção

Rua Maria Amélia Melo, 311 Bairro Santa Helena Belo Horizonte/MG Brasil CEP: 30642160

Telefones: (31)33899351/ (31)92321638

e-mail: davidson.prof@newtonpaiva.br

Eliza Helena de Oliveira Echternacht

Professor adjunto - Departamento de Engenharia de Produção

Rua Maria Amélia Melo, 311 Bairro Santa Helena Belo Horizonte/MG Brasil CEP: 30642160

Telefones: (31)33899351/ (31)92321638

e-mail:eliza@dep.ufmg.br

Recebido para publicação em: 18/10/2006

Aceito para publicação em: 05/12/2006 